\title{
Microscopic Thymoma
}

National Cancer Institute

\section{Source}

National Cancer Institute. Microscopic Thymoma. NCI Thesaurus. Code C45708.

A rare type of thymoma, composed of multifocal epithelial proliferations less than $1 \mathrm{~mm}$ in diameter. This type of thymoma usually occurs in myasthenia gravis patients without any macroscopic (gross) evidence of tumor. 